\title{
Numerical Simulation of Static Wind Coefficient and Flow Field of Box Girder of High Pier and Large Span Continuous Bridge
}

\author{
Zhipeng Zhou a,Guangbiao Jiang ${ }^{b}$ \\ Central South University of Forestry and Technology, China \\ azhouzhipeng945@126.com, b123372519@qq.com
}

\begin{abstract}
Keywords: CFD;High pier;long span continuous rigid frame bridge;Static wind coefficient
Abstract. Based on the CFD method, the numerical analysis of the box girder of Gulongshan Bridge is carried out.The static wind coefficient of the bridge box girder under different working conditions is extracted,The influence of the static wind coefficient on the wind speed, the angle of attack and the beam height is analyzed, and the variation characteristics of the flow field of the box girder under various working conditions are analyzed.The results show that the influence of wind speed, angle of attack and beam height on the lift coefficient of beam section is larger, the resistance coefficient is second, and the influence of moment coefficient is not significant. As the height of the box girder increases, the flow field becomes more complex.
\end{abstract}

\section{Introduction}

With the bridge span, the pier height is increasing, the structural quality is getting lighter, the structural stiffness is getting smaller and the structure damping is getting lower,leading to the increasing sensitivity to wind-induced effects. The static wind load, as one of the bridge control loads, is precisely predicted at the design stage.At present, the mainstream method is to put a reduced proportion of the segment model placed in the wind tunnel, through the experimental measurement of Static wind coefficient, and then through the "Highway Bridge Wind Design Code" provides the formula to calculate the static bridge static wind load.Meanwhile, the static coefficient aerostatic wind angle of attack curve is established based buffeting forces of the quasi-static theory. This makes it necessary to extract the Static wind coefficient of the bridge ${ }^{[1,2]}$.

In recent years,computational fluid dynamics (CFD) technology has been used in more and more projects with its advantages over time and wind tunnel tests, which are time-consuming, low-cost and visual ${ }^{[3,4]}$.At the same time, many scholars have been more fully validated CFD method for extracting three-point coefficient of the feasibility and reliability.

\section{Static wind coefficient}

The wind has a characteristic of flow,so it will have some deformation in the structure of the wind field.When the wind is uniform, the effect of air flow on the structure is equivalent to a static load.The ternary force coefficient is a set of dimensionless coefficients designed to describe the static wind load.

According to Bernoulli equation:

$\frac{1}{2} \rho U^{2}+P=$ constant

Where "U"is the incoming velocity.The flow rate faster on the"P"(pressure) value is smaller than the large flow rate point pressure value. The surface of the bridge section of the pressure difference between the surface of the integral,obtained by the cross-section of the lift load.Similarly, the area difference between the front and back surfaces of the bridge section is the resistance load of the bridge section.In addition, the lift force and the load resistance of the joint force point often does not coincide with the cross-shaped heart, then the force is bound to produce torque relative to the centroid.Therefore, the entire bridge section of the load by the lift force $F_{d}$, resistance $F_{l}$, torque $F_{m}$ three components, As shown in Fig 1. 


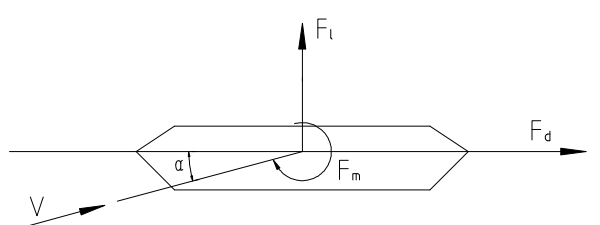

Fig.1 The three components of the wind load under the body axis
The existence of the bridge section changes the flow field distribution characteristics of the wind load is the root cause. Without changing the other external factors under the conditions of the impact, The wind loads produced by the two sections with similar shape are proportional to their characteristic dimensions.Thus, we introduce three dimensionless coefficients $C_{l}, C_{d}$, and $C_{m}$ for the convenience of describing the static wind loads with similar features.It can be expressed as ${ }^{[5]}$ :

$$
\begin{aligned}
& F_{l}=\frac{1}{2} \rho U^{2} C_{l} D \\
& F_{d}=\frac{1}{2} \rho U^{2} C_{d} B \\
& F_{m}=\frac{1}{2} \rho U^{2} C_{m} B^{2}
\end{aligned}
$$

Where" $\mathrm{D}$ "is the height of the bridge section," $\mathrm{B}$ "is the width of the bridge section.In order to uniform feature size and calculation convenience, this paper defines the Static wind coefficient,which is:

$F_{l}=\frac{1}{2} \rho U^{2} C_{l}^{\prime} B$

then: $C_{l}^{\prime}=C_{l} \frac{D}{B}$.

\section{The establishment of the calculation mode}

Project Overview.Gulongshan Bridge is located in Baise City, Guangxi Province, Jingxi County, Lake Town, the ancient Longshan Scenic Area.The bridge is a high-pier large-span curved rigid-framed bridge with a bridge span of $65 m+3 * 120 m+65 m$.

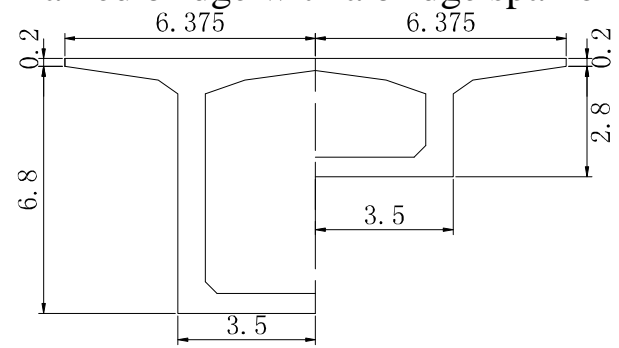

Fig.2 Schematic diagram of the cross-section and cross-section of the mid-span pier (unit:m)
The upper structure adopts the single-box single-chamber section, and the box-beam section size is: the roof is $12.75 \mathrm{~m}$, the bottom plate is $7.0 \mathrm{~m}$, the middle height is $3.0 \mathrm{~m}$, the top of the pier is $7.0 \mathrm{~m}$, and the beam is changed by 1.5 times parabola ${ }^{[6]}$,as shown in fig 2.

Calculate the condition.In order to accurately reflect the static wind response of box girder under different conditions, this paper simulates the cross section of box girder from three aspects: wind speed, wind angle

and beam height.In the wind speed, the maximum wind speed of $20.8 \mathrm{~m} / \mathrm{s}$ in the past three decades was obtained from the Chinese meteorological data network. The total distance of $2 \mathrm{~m} / \mathrm{s}-20 \mathrm{~m} / \mathrm{s}$ and $21 \mathrm{~m} / \mathrm{s}$ was $2 \mathrm{~m} / \mathrm{s}$ Conditions for simulation analysis.In the aspect of wind attack angle, according to the requirements of "Highway Bridge Wind Design Code", the simulation analysis was carried out at 0 degrees to plus or minus 10 degrees with a gradient of 2 degrees.Finally, in the aspect of beam height, the middle bridge crosses the top of the pier, and the cross section of $1 / 8,1 / 4,3,8,1 / 2$ span is simulated.

Computational domain and boundary conditions. The selection of the calculation domain and the boundary condition directly affects the accuracy of the calculation result.In this paper, the selection of domain and boundary conditions is shown in Fig 3, where B is the characteristic size, ie, the width of the beam ${ }^{[7]}$. 
Meshing and solving calculations. The purpose of meshing is to discretize the computational domain.In this paper, the grid is divided by ANSYS ICEM CFD14.0 software.The division pattern is dense and close, that is, the grid is changed in the violent position of the change of the flow field. In other positions, the excessive area is set up with the sparse grid and the dense grid, and the number of the grid is about 80,000 . The advantage of doing so is to ensure that the flow field simulation accuracy of the case to save a lot of computing time ${ }^{[8]}$.The grid diagram is shown in Figure 4.

The numerical simulator solver is FLUENT, the mathematical model is incompressible Renault $\mathrm{N}-\mathrm{S}$ equation. The turbulence model is standard $K-\varepsilon$ model, the turbulence intensity is $0.5 \%$, and the turbulence viscosity ratio is 10 .

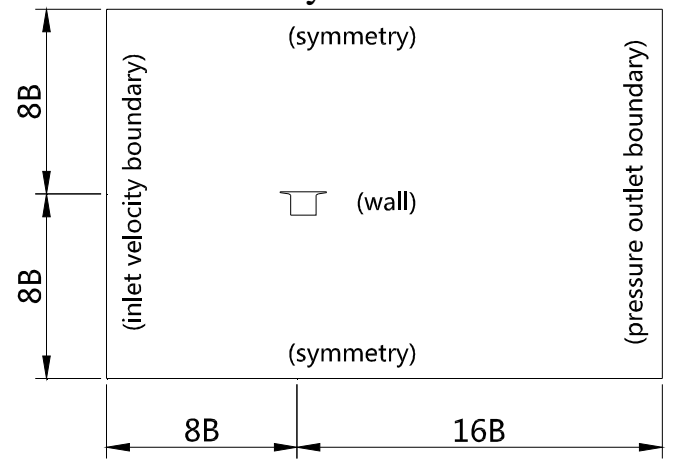

Fig.3 Computational domain and boundary conditions

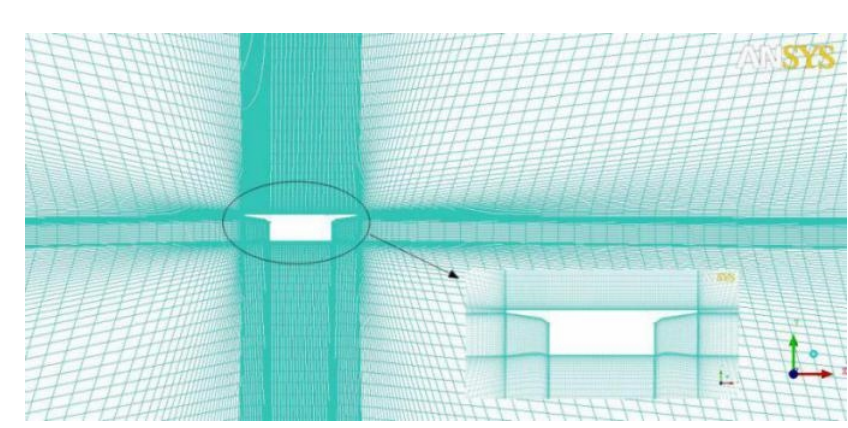

Fig.4 Grid overall and local schematic

\section{Analysis of Static Wind Coefficient and Flow Field under}

Analysis of Static Wind Coefficient and Flow Field at Different Wind Speeds.The wind field numerical simulation was carried out under different wind speed conditions at 0 degree wind angle. Now the results are processed as follows:

From Table 1, we can see that with the increase of wind speed, the drag confficient is slowly increasing from 0.2660 to 0.2727 .The lift coefficient is increasing from 0.4378 to 0.6429.The moment coefficient is slightly fluctuating between -0.1946 and -0.1988 , and the maximum absolute value appears at $8 \mathrm{~m} / \mathrm{s}$.

Table 1 Static wind coefficient table under different wind speed

\begin{tabular}{cccc}
\hline $\begin{array}{c}\text { Wind } \\
\text { speed(m/s) }\end{array}$ & $\begin{array}{c}\text { drag } \\
\text { confficient }\end{array}$ & $\begin{array}{c}\text { Lift } \\
\text { coefficient }\end{array}$ & $\begin{array}{c}\text { Torque } \\
\text { coefficient }\end{array}$ \\
\hline $\mathbf{2}$ & 0.2660 & 0.4378 & -0.1946 \\
$\mathbf{4}$ & 0.2673 & 0.5182 & -0.1980 \\
$\mathbf{6}$ & 0.2689 & 0.5574 & -0.1987 \\
$\mathbf{8}$ & 0.2700 & 0.5816 & -0.1988 \\
$\mathbf{1 0}$ & 0.2707 & 0.5983 & -0.1984 \\
$\mathbf{1 2}$ & 0.2711 & 0.6114 & -0.1980 \\
$\mathbf{1 4}$ & 0.2716 & 0.6213 & -0.1975 \\
$\mathbf{1 6}$ & 0.2720 & 0.6287 & -0.1970 \\
$\mathbf{1 8}$ & 0.2722 & 0.6350 & -0.1964 \\
$\mathbf{2 0}$ & 0.2725 & 0.6404 & -0.1960 \\
$\mathbf{2 1}$ & 0.2727 & 0.6429 & -0.1957 \\
\hline
\end{tabular}

From Fig 5 shows that the drag confficient, torque coefficient with the wind speed changes smaller; The lift coefficient is more sensitive to the change of wind speed, and increases with the increase of wind speed. The rising rate decreases with the increase of wind speed. 


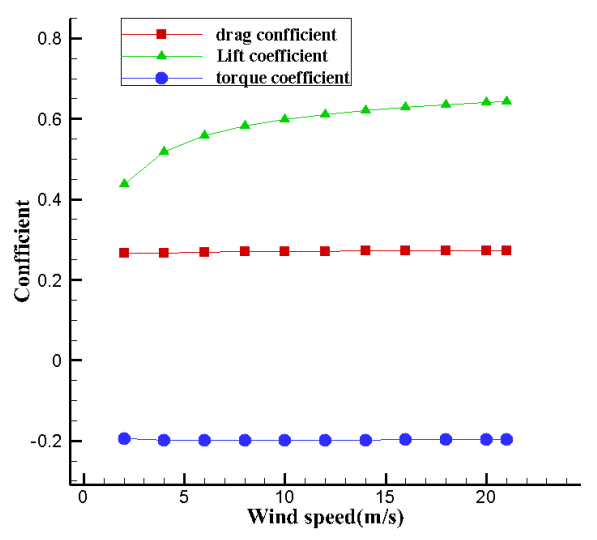

Fig. 5 Wind pressure curve at differentwind speeds
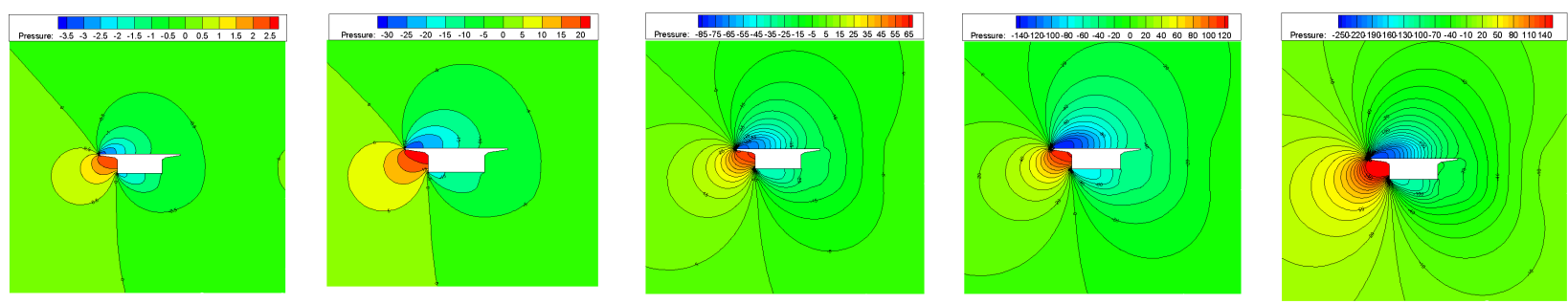

Fig. $62 \mathrm{~m} / \mathrm{s}, 6 \mathrm{~m} / \mathrm{s}, 10 \mathrm{~m} / \mathrm{s}, 14 \mathrm{~m} / \mathrm{s}, 18 \mathrm{~m} \mathrm{~s}$ wind pressure
From Fig 6,the peak value of the positive pressure at the wind speed appears at the junction of the windward surface of the box girder and the web, and the peak of the negative pressure appears on the windward side of the bridge.By comparing the difference between the positive and negative pressure peaks, it can be seen that the difference between the two increases with the increase of the wind speed.This also explains that the lift coefficient increases as the wind speed increases, and the difference between the positive and negative pressure on the surface of the box girder increases as the wind speed increases.

Analysis of static wind coefficient and flow field under different angles of attack.The mid-section of the box girder is selected and the wind field is simulated at a wind speed of $10 \mathrm{~m} / \mathrm{s}$.In this paper, the Static wind coefficient is calculated under the wind angle condition, that is, the flow direction is taken as the coordinate axis. The results are processed as follows:

From Table 2 we can see that the drag confficient between $0.2641 \sim 0.3588$, from the minimum value of the angle of attack -2 degrees to both sides of the increase.Lift coefficient between -0.0937 0.5946 , the larger range of change. The torque coefficient is between -0.1157 and -0.2066 , similar to the drag confficient, the minimum value is generated at -2 degrees, increasing to both sides.

Table 2 The coefficient of static winds at different angles of attack

\begin{tabular}{cccc}
\hline $\begin{array}{c}\text { Angle of attack } \\
(\boldsymbol{o})\end{array}$ & $\begin{array}{c}\text { drag } \\
\text { confficient }\end{array}$ & $\begin{array}{c}\text { Lift } \\
\text { coefficient }\end{array}$ & $\begin{array}{c}\text { Torque } \\
\text { coefficient }\end{array}$ \\
\hline-10 & 0.3588 & -0.0937 & -0.1157 \\
-8 & 0.3226 & 0.0340 & -0.1425 \\
-6 & 0.2885 & 0.2044 & -0.1734 \\
-4 & 0.2671 & 0.3732 & -0.1970 \\
-2 & 0.2641 & 0.5003 & -0.2066 \\
0 & 0.2709 & 0.5946 & -0.1957 \\
2 & 0.2896 & 0.5478 & -0.1676 \\
4 & 0.3076 & 0.4759 & -0.1693 \\
6 & 0.2969 & 0.3709 & -0.1637 \\
8 & 0.3285 & 0.3360 & -0.1620 \\
10 & 0.3278 & 0.3207 & -0.0649 \\
\hline
\end{tabular}

At the same time with Fig 7 we can see that the lift coefficient of the largest change in the degree of 0 degrees to the maximum value of both sides of the decline, and the negative attack angle side of the rate of decline is significantly greater than the angle of attack. The reason is that the upper surface is flat with the lower surface, with the change of the angle of attack above the surface of the main surface, the air flow faster. 


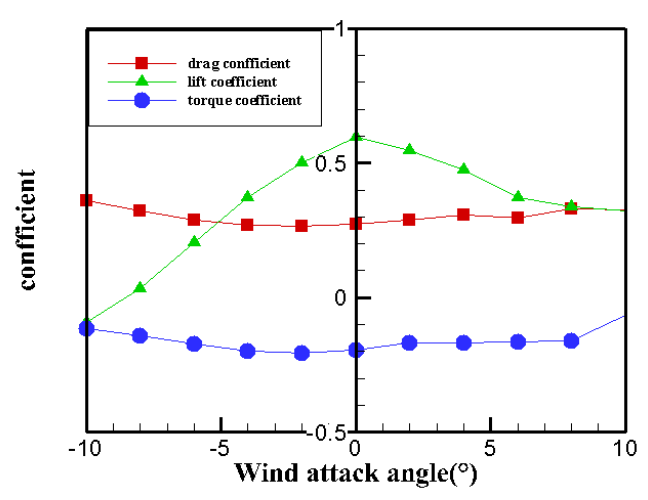

Fig. 7 The curve of static wind coefficient under different angles of attack
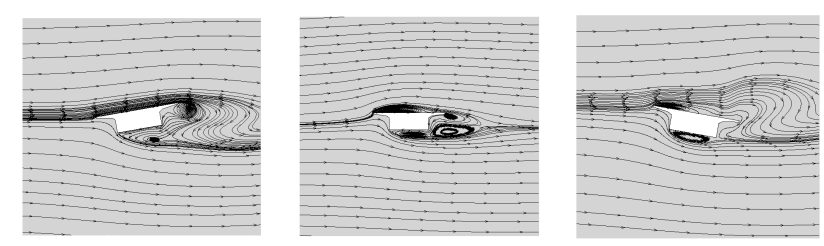

Fig.8 -10,0,10 degree attack line flow chart
Fig 8 shows that the 0 degree angle of attack than the $+10,-10$ degrees under the angle of attack more richer flow. Which -10 degrees when the angle of attack, the beam near the surface of the streamline than +10 degrees angle of attack smooth.Indicating that the beam section under the negative angle of the box under the beam force is better than the angle of attack.It can be seen from Fig. 9 that the change of the angle of attack has a great influence on the pressure distribution of the flow field of the box girder, especially the negative pressure zone.In the -10 degree angle of attack, the tail negative pressure area from the phenomenon.
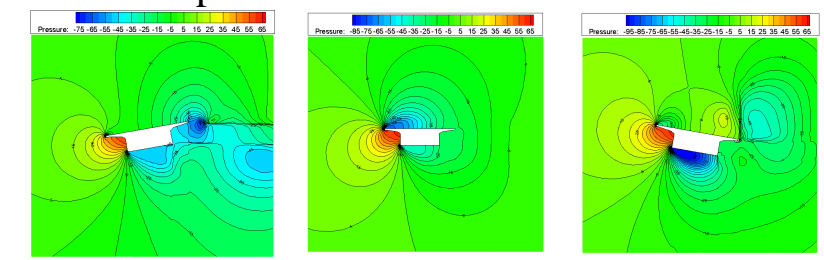

Fig.9 -10,0,10 degrees attack pressure cloud

Analysis of Static Wind Coefficient and Flow Field of Different Beam Height.In this paper, the beam height is based on the cross section of the bridge in the position of the decision, so the cross-section height is not a linear proportion.The results are processed as follows:

Table 3 The static wind coefficient of different beams

\begin{tabular}{cccc}
\hline $\begin{array}{c}\text { Position } \\
\text { (step astride) }\end{array}$ & $\begin{array}{c}\text { drag } \\
\text { confficient }\end{array}$ & $\begin{array}{c}\text { Lift } \\
\text { coefficient }\end{array}$ & $\begin{array}{c}\text { Torque } \\
\text { coefficient }\end{array}$ \\
\hline $4 / 8$ & 0.2707 & 0.5983 & -0.1984 \\
$3 / 8$ & 0.3007 & 0.6291 & -0.1917 \\
$2 / 8$ & 0.3937 & 0.6636 & -0.1656 \\
$1 / 8$ & 0.6104 & 0.9810 & -0.2087 \\
0 & 0.6959 & 0.9467 & -0.1754 \\
\hline
\end{tabular}

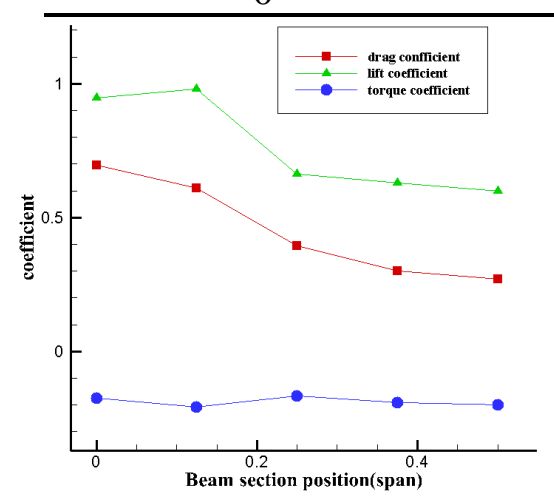

Fig.10 The Curve of Static Wind Coefficient with Different Beam Height
Combined with Table 3 and Fig 10, the drag confficient and the lift coefficient with the beam height change is obvious. The drag confficient is between 0.2707 and 0.6959 , and decreases with the decrease of beam height. The lift coefficient is between 0.5983 and 0.9467 , and decreases with the decrease of beam height.The torque coefficient is between -0.1656 and 0.2087 , and the variation of the beam is not obvious.

From Fig. 11, as the height of the box girder increases, the flow field becomes more complex.Mainly as the beam height increases, the negative pressure range to the tail movement, 2/8 beam high negative pressure zone gradually out of the box surface, and began to dissipate. 

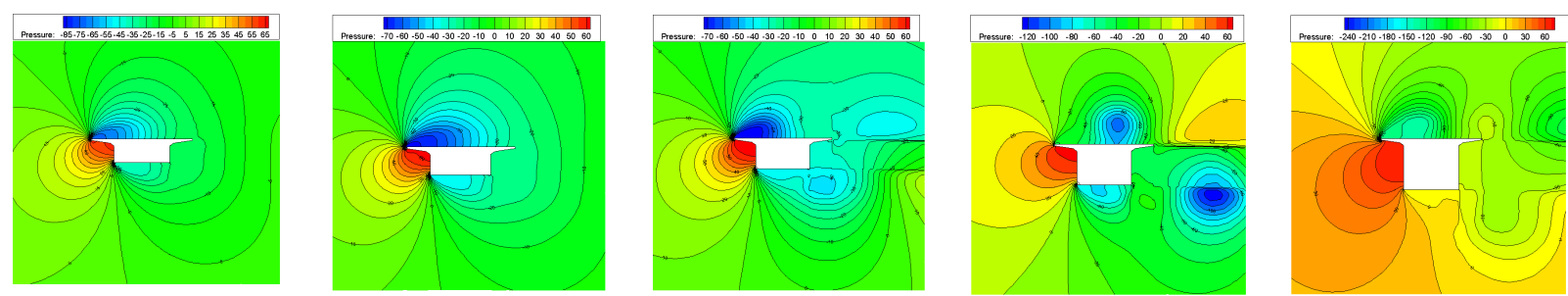

Fig 11 4/8 span, 3/8 cross, 2/8 span, 1/8 span, 0 cross section pressure cloud

\section{Conclusions}

Based on the Gulongshan Bridge, this paper analyzes the static wind response of the bridge box section from multiple angles, and draws the following conclusions:

First, for the Gulongshan Mountain Bridge, the cross-section has a maximum wind speed of $21 \mathrm{~m} /$ s over the years, the drag confficient is 0.2727 , the lift coefficient is 0.6429 and the torque coefficient is -0.1957 .In the wind speed $10 \mathrm{~m} / \mathrm{s}$, the more close to the top of the pier section, lift coefficient, the greater the drag confficient.

Second, the effect of wind speed on the lift coefficient is the most obvious, and with the increase of wind speed, the lift coefficient gradually increases and the growth rate decreases. The peak value of the positive pressure at the wind speed appears at the junction of the windward side of the box girder and the web, and the negative pressure peak appears on the side of the bridge near the windward side.

Third, the effect of the angle of attack on the lift coefficient is most obvious. When the wind speed is $10 \mathrm{~m} / \mathrm{s}$, the maximum value of the lift coefficient appears at 0 degree angle of attack, and decreases at the same time to the positive and negative angle. The change of the angle of attack has little effect on the drag confficient and the torque coefficient. Wind speed at $10 \mathrm{~m} / \mathrm{s},-10$ degrees when the angle of attack, the beam near the surface of the streamline near +10 degrees angle of attack smooth.Indicating that the beam section under the negative angle of the box under the beam force is better than the angle of attack.

Fourth, the ternary force coefficient is sensitive to the change of the cross section height, the lift coefficient, the maximum drag confficient and the torque coefficient.As the height of the box girder increases, the flow field becomes more complex.Mainly, as the beam height increases, the negative pressure zone moves to the tail, and the negative pressure zone gradually withdraws from the surface of the box girder and begins to dissipate.

\section{References}

[1] Zhengqing Chen. Bridge wind engineering[M].BeiJing:China Communications Press, 2005.In Chinese

[2] Haifan Xiang,Yaojun Ge. Challenges and Basic Research on Wind - Resistant Technology of Long - span Bridges[J]. Chinese Engineering Science, 2011, 13(09): 8-21.In Chinese

[3] Zhengqing Chen,Guangdong Liu.Some New Developments in the Study of Bridge Wind Engineering[J].Engineering mechanics, 2006, 23(S2): 93-111.In Chinese

[4] Haifan Xiang,Airong Chen.New Advances in Research on Wind Resistance of Extra Large Span Bridges[J]. Journal of Civil Engineering Society, 2003, 36(4): 1-8.In Chinese

[5] Ministry of Communications of the People 's Republic of China. Code for wind-resistant design of highway bridge(JTG T D60-01-2004).Beijing:China Communications Press,2004.In Chinese

[6] Bin Huang,Jiejue Wang,Peixin Long.Structural Analysis of Construction Stage of Continuous Rigid Frame Bridge with High Diameter and Small Radius Curve[J].Road construction, 2014, 39(06):266-218+30.In Chinese 
[7] Yao Liu,Zhengqing Chen,Zhitian Zhang.Numerical Simulation of Static Wind Coefficient of Box Girder by CFD[J].Vibration and shock, 2010, 29(1): 133-137.In Chinese

[8] Wen Deng,Yaojun Ge,Fengchan Cao.Comparison of Turbulent Model in Numerical Recognition of Static wind of Bridge Closed Box Girder[J]. Shanghai Highway, 2006, (4):5,36-40.In Chinese 